\title{
UM ESTUDO SOBRE AS PRINCIPAIS CAUSAS DE EVASÃO DE ALUNOS EM CURSOS EAD. COMO REVERTER ESSE QUADRO?
}

\author{
SÃO PAULO/SP MAIO/2018 \\ Genivaldo Carlos da Silva - UAM - genivaldo.silva@anhembi.br \\ Agostinho Augusto Figueira - UAM - agostinho.figueira@eadlaureate.com.br \\ Lucia Maria Tavares - UAM - tavares.lucia@gmail.com
}

Tipo: Investigação Científica (IC)

Natureza: Planejamento de Pesquisa

Categoria: Pesquisa e Avaliação

Setor Educacional: EDUCAÇÃO SUPERIOR

\begin{abstract}
RESUMO
Este artigo discorre sobre as razões da evasão dos alunos matriculados em cursos de Educação à Distância (EaD). Para isso, sendo realizada uma pesquisa de revisão bibliográfica, baseada em livros e, especialmente, em artigos que apresentem estudos quantitativos e qualitativos a respeito do tema. $A$ ideia é apresentar os principais fatores envolvidos na evasão dos alunos de EaD, a fim de oferecer parâmetros que auxiliem no aprimoramento destes cursos. E, assim, efetivamente, contribuir para que a educação no Brasil seja acessível e democrática.
\end{abstract}

Palavras-chave: Educação à Distância - Evasão - Causas 


\section{Introdução:}

Especialmente na última década, a Educação tem experimentado um grande salto em relação aos métodos de ensino, demonstrando um processo de mudança profunda no modelo de escola, visando atender às necessidades de um público bastante distinto daquele para quem o modelo tradicional foi criado.

O modelo tradicional contempla um tutor ou professor que detém o conhecimento e o transmite aos seus alunos, em pequenas turmas, sentados em fileiras dentro de uma sala de aula. Subjetivamente este modelo ressalta a questão da hierarquia, uma vez que o conhecimento é transmitido apenas pelo docente, não permitindo a interação e contribuição dos alunos no processo de ensino e aprendizagem. Não considera a bagagem cultural e social do aluno, trazendo conteúdos estanques e desvinculados da realidade (ARAÚJO, ARANTES, KLEIN, 2010).

Trata-se de uma educação engessada e direcionada para a formação de profissionais específicos, mantendo o padrão e estilo de vida de uma elite, se caracterizando como excludente, por não permitir o acesso da população mais pobre ou de raças diferentes.No entanto, com o passar dos séculos, aos poucos, foram ocorrendo mudanças culturais que enfatizaram a necessidade de uma educação inclusiva e acessível a todos.No Brasil, o processo de democratização da escola ficou mais evidente na última década, especialmente após a Constituição de 1988, com o reconhecimento dos direitos fundamentais e do princípio da dignidade humana, que passou a inspirar toda a legislação, especialmente em relação ao direito à igualdade e educação de qualidade acessível a todos.

Dentre as iniciativas decorrentes da previsão legal, houve a criação de bolsas de estudos custeadas pelo Estado (PROUNI, por exemplo) e, especialmente, a partir do desenvolvimento das tecnologias de comunicação, o surgimento (ou aprimoramento) dos cursos à distância.Assim, a criação de cursos EaD realizados pela internet favoreceram essa interação. Porém, ainda, a aceitação e reconhecimento social destes cursos ainda deixam a desejar na sociedade, por diversas razões, que giram em torno da qualidade do ensino e da efetiva participação dos alunos.

Por um lado, o desenvolvimento de cursos EaD revolucionou a Educação, no sentido da democratização, ou seja, permitindo o acesso de alunos que, de outra maneira, não conseguiriam estudar, especialmente nos cursos superiores e pós-graduação. A Internet favoreceu que os cursos $\mathrm{EaD}$ chegassem aos locais mais longínquos do País, possibilitando não apenas o acesso, mas também a inclusão de pessoas com 
necessidades especiais, por retirar as barreiras temporais e geográficas. O problema é que, por outro lado, a evasão dessas modalidades de cursos é muito alta, demonstrando que há necessidade de se identificar as dificuldades que levam os alunos a não levar a termo o curso pretendido. Nesse sentido, alguns artigos apresentam pesquisas que apontam essas causas.

Embora existam muitas razões pelas quais os alunos abandonem os cursos universitários, no caso dos cursos on line, há algumas particularidades, tais como: o isolamento, a falta de conexão com a internet e outros problemas tecnológicos, pode influenciar a desistência. Mas há razões particulares dos indivíduos, inclusive por se tratar de um público que, por algum motivo, não consegue ou não tem acesso a cursos presenciais.Porém, o cenário da educação vem se modificando a medida que crescem os cursos de educação on line. Desenvolvimentos no uso educacional de computadores, software e redes distribuídas levaram a questões sobre a eficácia deste novo método de entrega educacional e as condições que favorecem resultados promissores para os alunos. Por isso, verificar a taxa de abandono e dos alunos que concluem o curso pode ser um indicador da qualidade do programa oferecido.

A questão é que ainda há poucos estudos a respeito, para que seja possível verificar a qualidade e os pontos de melhoria necessários nessa modalidade de ensino.As estimativas sobre o desgaste nos programas de pós-graduação no ensino superior não estão disponíveis, em parte devido à diversidade dos programas e na dificuldade de estabelecer métricas comuns que permitam comparações de programa de conclusão do programa e taxas de abandono. Porém, sabe-se que as taxas de evasão para educação a distância são mais altas do que aqueles para programas e cursos presenciais. Alguns estudos estimam aproximadamente que os alunos matriculados na educação à distância têm duas vezes mais chances de desistir do que os estudantes de cursos presenciais.

\section{FUNDAMENTAÇÃO TEÓRICA}

A modalidade de educação a distância (EaD) se iniciou no Brasil, por volta de 1904, quando foram criados os cursos por correspondência, que chegaram a atender mais de 35 milhões de alunos. Numa fase posterior, na década de 1960, foram aprimorados os materiais didáticos impressos e foi desenvolvida a tele-educação, por meio da comunicação de massa (rádio e televisão). (FORMIGA, 2004).A EaD trata-se de uma das modalidades que efetivamente mais cumprem o papel de favorecer o amplo acesso à educação, permitindo a formação e qualificação de profissionais. Também é considerada uma ferramenta muito importante de transmissão do conhecimento, de acesso e democratização da informação (MAIA, MATTAR, 2007). 
Na definição do MEC (2016, p. 1):

Educação a distância é a modalidade educacional na qual alunos e professores estão separados, física ou temporariamente e, por isso, faz-se necessária a utilização de meios e tecnologias de informação e comunicação. Essa modalidade é regulada por uma legislação específica e pode ser implantada na educação básica (educação de jovens e adultos, educação profissional técnica de nível médio e na educação superior).

O Censo da Educação Superior de 2016, realizado pelo INEP, identificou que o ensino presencial sofreu queda anual de $0,08 \%$ nas matrículas, enquanto no ensino a distância (EAD) houve aumento de 7,2\% (INEP, 2016).

Em relação ao ingresso nos cursos de graduação e EaD, tem-se:

Em 2016, quase 3 milhões de alunos ingressaram em cursos de educação superior de graduação. Desse total, $82,3 \%$ em instituições privadas. Após uma queda observada em 2015, o número de ingressantes teve um crescimento de 2,2\% em 2016. Isso ocorreu porque a modalidade a distância aumentou mais de $20 \%$ entre os dois anos, enquanto nos cursos presenciais houve um decréscimo no número de ingressantes de 3,7\%. (INEP, 2016, p.1)

Tais números demonstram que os cursos EaD vêm se tornando mais populares, atraindo mais pessoas, possivelmente devido aos preços mais reduzidos e, especialmente, por permitir que o aluno estude no horário que melhor the atender $\mathrm{e}$ onde quer que esteja, desde que tenha acesso à internet.

Quanto aos concluintes, os dados referentes a 2016 são os seguintes:

(...), mais de um 1,1 milhão de estudantes concluíram a educação superior. O número de concluintes em cursos de graduação presencial teve aumento de 2,4\% em relação a 2015. A modalidade a distância diminuiu $-1,3 \%$ no mesmo período.

Entre 2015 e 2016, o número de concluintes na rede pública aumentou 2,9\%. Já na rede privada a variação positiva foi de $1,4 \%$.

No período de 2006 a 2016, a variação percentual do número de concluintes em cursos de graduação foi maior na rede privada, com $62,6 \%$, enquanto na pública esse crescimento foi de $26,5 \%$ no mesmo período. (INEP. 2016 , p.1)

Aliás, pode-se dizer que o grande crescimento na oferta de cursos na modalidade EaD na rede privada, com custos mais reduzidos e maior flexibilidade para o aluno, vem favorecendo o acesso das diversas camadas da população, especialmente a classe trabalhadora mais pobre, especialmente mulheres, ao ensino de nível superior. Nesse sentido, destacando-se os cursos de licenciatura visando a formação de professores de educação infantil, fundamental e médio.De acordo com o censo da ABED (2014), a evasão é um dos maiores desafios a serem superados nos cursos EaD, com índices que 
alcançavam 25\%.Deste modo, destaca-se a importância de um planejamento e sistema de curso motivador, que envolva mais o aluno, que crie oportunidades para as trocas de experiências e de conhecimentos, não deixando que o aluno se sinta apenas mais um dos matriculados na instituição.Vincent Tinto (1975) criou o modelo Teórico de Tinto abrange o modelo de integração dos estudantes, nas seguintes vertentes: interna fatores relacionados à experiência anterior a entrada do aluno na graduação e suas características individuais; e a teoria de integração, referente a avaliação a partir da performance em notas e pela integração social, ou seja, a integração entre discentes e docentes, bem como a participação em atividades complementares.

As experiências dos alunos dentro da instituição, mas também fatores externos, podem afetar as crenças, atitudes e decisões. Um modelo de convergência sugere a combinação das principais proposições contidas nessas duas teorias.Martins et al. (2013) investigaram os fatores que levam a evasão em cursos de licenciatura na Universidade Aberta do Brasil, considerando tratar-se de um fenômeno complexo que exige atenção da gestão educacional. A pesquisa foi realizada contando com a participação de 74 alunos matriculados no segundo semestre de 2011 e que desistiram no ano seguinte, representando $44 \%$ de evasão naquela instituição. Tal estudo revelou que a evasão decorreu de motivos diversos, mais relacionados a questões pessoais, inadequação de expectativas e falta de tempo para os estudos do que a fatores referentes à estrutura, oferta e qualidade do curso.

Aliás, é bom frisar que a evasão é verificada na grande maioria dos cursos universitários, sejam eles presenciais ou não, por motivos semelhantes aos identificados por Martins et al. (2013). Mediante ao cenário de grande índice de desemprego e necessidade de continuidade nos estudos, visando uma melhor capacitação profissional, muitas pessoas têm procurado os cursos de $\mathrm{EaD}$, aumentando tanto a procura quanto a oferta desses cursos. A busca pela igualdade de oportunidades requer a disponibilização do acesso a uma educação de qualidade para todas as pessoas, bem como a construção de uma escola realmente democrática, que tenha como finalidade a inclusão social.Tanto na rede pública quanto privada, as iniciativas em favor da ampliação do acesso à educação necessitam ser efetivadas. E um caminho muito importante é a modalidade de educação a distância, por permitir o acesso de um maior número de pessoas ao ensino de todos os níveis, especialmente de nível superior.

Além disso, observa-se predominância de oferta das licenciaturas no sistema público de ensino superior, principalmente devido às ações de fomento da Universidade Aberta do Brasil (UAB). Nesse contexto, em que a destinação de recursos públicos para a formação de professores é expressiva e existe crescente oferta de cursos a distância 
notadamente de formação de professores, se faz necessário investigar as implicações de tal fenômeno para o sucesso dos estudantes nos cursos, visto que a meta principal da $U A B$ é a formação de novos profissionais que atuarão na educação básica (MARTINS et al., 2013).Segundo Mill e Carmo (2012), a gestão educacional em EaD tem especificidades que exigem um planejamento e atuação adequadas, especialmente levando-se em consideração a evasão e a permanência nos cursos, bem como quanto ao sistema de avaliação.Outros estudos exploraram as mesmas relações, embora focalizando a formação de professores. (Martins e Hokari, 2011; Martins, Amaral, Serafim e Berti, 2012).

Conforme Crampton, Ragusa e Cavanagh (2012) e Silva (2009), o domínio e o uso das tecnologias também influenciam o desempenho dos alunos de $\mathrm{EaD}$, pois, se o aluno tem dificuldades para utilizar o computador e não tem acesso a uma boa.No entanto, outras variáveis podem interferir no processo de ensino e aprendizagem dos cursos EaD. Um dos aspectos verificados se refere ao gênero dos alunos, sendo demonstrado que este não exerceu influência no desempenho. Já em relação a idade e renda mensal, estes aspectos parecem influenciar o sucesso ou desistência dos alunos (MARTINS; HOKARI, 2011).

Diante disso, pode-se afirmar que, em relação às variáveis sociodemográficas, o público que escolhe a modalidade de educação a distância tem características distintas daqueles que realizam cursos presenciais. Além disso, havendo a influência de outras variáveis, tais como: o uso das tecnologias, a idade e a renda familiar. Entretanto, tais parâmetros não são suficientes para se determinar a razão do melhor ou pior desempenho dos estudantes em cursos EaD, bem como o fenômeno da evasão.Em pesquisa de campo realizada por Bittencourt e Mercado (2014), a evasão no Curso Piloto de Administração a distância da UFAL/UAB atingiu 70\% no primeiro ano, sendo identificadas as seguintes causas: a) problemas internos da instituição de ensino (insatisfação com professores e tutores); b) problemas com a plataforma tecnológica; c) insatisfação dos alunos com os encontros presenciais realizados nos finais de semana que não atendiam às expectativas.

Em estudo realizado por Almeida et al. (2013), envolvendo dois cursos a distância da Universidade de Brasília, as principais causas identificadas foram: a) percepção da falta de apoio acadêmico e administrativo; b) falta de apoio da instituição e problemas quanto a interação entre alunos e professores; c) falta de habilidade, recursos ou de fatores situacionais; d) problemas pessoais dos alunos.Em estudo semelhante, Tamariz e de Souza (2015) indicaram que a baixa qualificação dos professores responsáveis pelo conteúdo dos cursos de EaD pode ser uma das causas para a evasão, já que somente 
algumas instituições $(4,3 \%)$ contam com equipes formadoras de conteúdo interativo e adaptado às necessidades dos alunos dos cursos EaD. Aliás, é comum que os cursos EaD empreguem os

Além disso, a evasão não pode ser interpretada somente a partir da abordagem quantitativa e estatística (MARTINS et al., 2013).Uma investigação mais abrangente sobre as razões para a evasão na EaD, envolvendo 510 participantes, realizada por Araújo; Oliveira e Marchisotti (2016), verificou os seguintes aspectos: a) falta de tempo do aluno para dedicar-se aos estudos; b) conteúdo do curso não atendeu às expectativas do aluno; c) o curso não correspondeu aos anseios dos alunos.Destaca-se, ainda, a necessidade de criação de parcerias com empresas e organizações públicas ou privadas que possam disponibilizar vagas de estágio ou contribuir, de alguma maneira (palestras, visitas etc.), para que os alunos de cursos EaD tenham oportunidades de aprendizagem prática, tornando o processo de ensino e aprendizagem muito mais significativo e motivador.

Considerações finais

A EaD pode atender às necessidades de uma diversas pessoas, seja em relação ao custo reduzido ou pela possibilidade de adequação dos horários de estudos, conciliando às condições familiares e de trabalho do indivíduo.Enfatizando-se o lado da instituição, torna-se fundamental um trabalho e planejamento que favoreça a motivação do aluno, de modo que o mesmo não se sinta isolado e sem as respostas que procura.Desse modo, o papel do tutor é muito importante, pois é ele o principal representante da instituição, que está mais próximo do aluno. Assim, devendo estar atento ao aluno, para que possa continuamente verificar o aproveitamento e a motivação do aluno, buscando incentivá-lo a persistir.

Além disso, a instituição necessita inovar sempre, buscando diferenciais, promovendo encontros culturais e acadêmicos, inclusive on line, para que todos os alunos possam participar e se sentir parte do grupo, mesmo estando geograficamente longe.Além disso, a escola necessita considerar a diversidade cultural, a coexistência de diferenças e a interação entre indivíduos de diferentes identidades culturais. A falta de conteúdos culturais reduz as possibilidades da população mais pobre acessar o mundo cultural e 0 desenvolvimento de suas capacidades intelectuais.

Aliás, a justiça social deve começar na escola. Para tanto, é urgente que seja alcançado um consenso nacional entre educadores, diretores de instituições de serviços públicos, políticos, pesquisadores e sindicatos sobre a valorização das escolas, do conhecimento 
escolar e, consequentemente, do trabalho do professor ou tutor, pois que são os principais agentes para a qualidade da educação. E, assim, favorecendo a redução da evasão escolar.

\section{REFERÊNCIAS}

ABBAD, G.; ZERBINI, T.; SOUZA, D. B. L. Panorama das pesquisas em Educação a Distância no Brasil. Estudos de Psicologia (UFRN), v. 15, p. 291-298, 2010.

ABED, Associação Brasileira de Educação a Distância. 2014. Censo EaD.br 2014: Relatório analítico de aprendizagem a distância no Brasil. Disponível em: http://www.abed.org.br/site/pt/. Acesso em: 20 abr. 2018.

AMIDACI, C. Evasão no ensino superior a distância: o curso de licenciatura em matemática a distância da Universidade Federal Fluminense/CEDERJ7 - RJ. Brasília/DF, 2004. (Dissertação de mestrado, UNB - Brasília).

ALMEIDA, O. C. D. S. D., ABBAD, G., MENESES, P. P. M., \& ZERBINI, T. Evasão em cursos a distância: fatores influenciadores. Revista Brasileira de Orientação Profissional, 14(1), 19-33, 2013.

ARAÚJO, Nathalia Tavares de Freitas; OLIVEIRA, Fátima Bayma de; MARCHISOTTI, Gustavo Guimarães. Razões para a evasão na Educação a Distância. FGV - Rio de Janeiro, junho 2016. Disponível em: http://www.abed.org.br/congresso2016/trabalhos/326.pdf. Acesso em: 20 mar.2018.

ARAÚJO, Ulisses F.; ARANTES, Valéria Amorim; KLEIN, Ana Maria. Escola, comunidade e novas configurações da educação. 2010. Disponível em: http://www.e scoladavila.com.br/html/outros/2010/30_anos/pdf_30/30_textos/29_ulisses.pdf. Acesso em: 20 abr. 2018.

BITTENCOURT, I. M., \& MERCADO, L. P. L. Evasão nos cursos na modalidade de educação a distância: estudo de caso do Curso Piloto de Administração da UFAL/UAB. Revista Ensaio: Avaliação e Políticas Públicas em Educação, 22(83), 465-504, 2014.

BIZARRIA, F. P. D.A., DA SILVA, M. A., TASSIGNY, M. M., \& CARNEIRO, T. C. J. Papel do tutor no combate à evasão na EAD: percepções de profissionais de uma instituição de ensino superior. Educação, Ciência e Cultura, 20(1), p-85, 2015. 
CAMPOS, L. C.; MARQUES, E.V. Educação a Distância: estudo das Habilidades Tecnológicas e Desempenho do Discente. In: XXXVI Encontro da Anpad. Rio de Janeiro, RJ. 2012. Disponível em: http://www.anpad.org.br/diversos/trabalhos/EnANPAD lenanpad_2012/ADI/Tema\%2001/2 012_ADI1961.pdf. Acesso em: 19 abr. 2018.

CRAMPTON, A.; RAGUSA, A. T.; CAVANAGH, H. Cross-discipline investigation of the relationship between academic performance and online resource access by distance education students. In: Research in Learning Technology, vol. 20, 2012.

DAUDT, S. I. D., \& BEHAR, P. A. A gestão de cursos de graduação a distância e o fenômeno da evasão. Educação, 36(3), 412-421, 2013.

FORMIGA, M. Educação Superior, Educação a Distância e Educação Corporativa. In: Seminário Bayma-FGV, Julho 2008, Rio de Janeiro: FGV Rio, julho 2008.

INEP. Censo da Educação Superior. Mec e Inep divulgam dados do Censo da Educação Superior 2016. Publicado em 31.08.2017. Disponível em: http://portal.inep.gov .br/artigo/-/asset_publisher/B4AQV9zFY7Bv/content/mec-e-inep-divulgam-dados-docenso-da-educacao-superior-2016/21206. Acesso em: 20 abr. 2018.

LACERDA, F.K.D; CORREA, P. S. Ead e evasão no pólo de Nova Friburgo: identificando causas e propondo soluções. VIII Congresso Brasileiro de Ensino Superior a Distância. Anais do ESUD-2011: UNIREDE, 2011.

LAGUARDIA, J.; PORTELA, M. Evasão na educação a distância. ETD - Educação Temática Digital. Campinas, v.11, n.1, p.349-379, dez. 2009.

MAIA, C.; MATTAR, J. ABC da EaD: a Educação a Distância hoje. 1. ed. São Paulo: Pearson, 2007.

MARTINS, Ronei Ximenes; SANTOS, Telsuita Laudomira P. Santos; FRADE, Elaine das Graças; SERAFIM, Luciana Batista. Por que eles desistem? Estudo sobre a evasão em cursos de licenciatura à distância. ESDUD 2013 - X Congresso Brasileiro de Ensino Superior a Distância. Belém - PA, 11 a 13 de junho de 2013 - UNIREDE.

MARTINS. R. X; HOKARI, A. Educação a Distância é para todos? Um estudo exploratório sobre possíveis preditores do sucesso acadêmico. VIII Congresso Brasileiro de Ensino Superior a Distância. ESUD-2011: UNIREDE, 2011. 
MEC - Ministério da Educação. 2016. O que é educação a distância? Disponível em: ht tp://portal.mec.gov.br/escola-de-gestores-da-educacao-basica/355-perguntas-frequentes -911936531/educacao-a-distancia-1651636927/12823-o-que-e-educacao-a-distancia.

Acesso em: 20 abr. 2018.

MEC; INEP. Resumo Técnico. Censo da Educação Superior de 2011. Disponível em: http://download.inep.gov.br/download/superior/censo/2011/resumo_tecnico_censo_educ acao_superior_2011.pdf. Acesso em: 18 abr. 2018.

MILL. D.; CARMO, H. Análise das dificuldades de educadores e gestores da educação a distância virtual no Brasil e em Portugal. SIED: EnPED-Simpósio Internacional de Educação a Distância e Encontro de Pesquisadores em Educação a Distância, 2012.

SANTOS, E. M.; OLIVEIRA NETO, J. D. Evasão na educação a distância: identificando causas e propondo estratégias de prevenção. Revista Científica de Educação a Distância. v.2, n.2, dez.2009.

SANTOS, A. G. R. A evasão nos cursos de graduação a distância UAB/Unimontes no polo de São João da Ponte/MG. Revista Multitexto, 2(1), 30-34, 2013. 